\title{
Explaining the Impact of Disabled Children' Engagement with Physical Activity on Their Parents' Smartphone Addiction Levels: A Sequential Explanatory Mixed Methods Research
}

\author{
Cemal Gündoğdu ${ }^{1}$, Yalın Aygün ${ }^{1}$, Mehmet Ilkım ${ }^{1}$, Şakir Tüfekçi ${ }^{1}$ \\ ${ }^{1}$ Faculty of Sport Sciences, Inonu University, Malatya, Turkey \\ Correspondence: Yalın Aygün, Faculty of Sport Sciences, Inonu University, 44280, Malatya, Turkey.
}

Received: December 2, 2017

Accepted: January 9, 2018

Online Published: January 20, 2018

doi:10.11114/jets.v6i2.2836

URL: https://doi.org/10.11114/jets.v6i2.2836

\begin{abstract}
In this research, quantitative findings and qualitative follow-up themes were used to quantify, conceptualize and finally try to explain the impact of disabled children' engagement with physical activity on their parents' smartphone addiction levels. An initial phase of quantitative investigation was conducted with 116 parents. Analyses of statistical trends indicated that male parents use smartphones more often than female. Furthermore, quantitizing data towards parents' smartphone addiction showed that parents watching their disabled children during physical activity exhibit more smartphone-addicted behaviors than non-watching parents. Finally, data obtained from quantitative findings revealed that levels of smartphone addiction of parents whose disabled children participated in more than 60 minutes of physical activity were greater than the levels of smartphone addiction of parents whose disabled children participated in 60 minutes of physical activity. With no adequate theoretical explanation for these results, a follow-up explanations phase of qualitative investigation was conducted with 5 parents. Analyses of interview data emerged three themes: (a) Male dominance in smartphone use, (c) parents passive participation in physical activity with or without smartphones and (b) levels of smartphone addiction among parents in terms of duration of their children daily physical activity engagement.
\end{abstract}

Keywords: sequential explanatory, smartphone addiction, physical activity, parenting, disabled children

\section{Introduction}

Despite its apparent appeal to thousands of disabled children and their parents, there might be a psychological problem associated with physical activity engagement. Why and how parents exhibit addicted behaviors to smartphone depending on their disabled children' engagement with physical activity might differ among parents. One participant' statements connected to the epistemological position encapsulated in the research, and grounded within the specific context of the research problem was highlighted, for example:

Sureyya: When parents are separated from their children, that is, their responsibilities over children decrease, their dependence on smartphones increase more. Special children' participation in physical activity under the supervision of a health care provider, a coach or a teacher is also the main reason for different levels of smartphone addiction among parents.

A core assumption of this sequential explanatory mixed methods approach used in this present research is combining statistical trends (quantitative data) with stories and personal experiences (qualitative data) to answer and link the different levels of research questions at the level of explanation. This collective strength provides a better understanding of the research problem than either form data alone (Creswell, 2014). This article first introduces the theoretical background of the research and its context. Then it presents the methodological stage of the quantitative and qualitative strand side by side. The article gives a perspective of both quantitative (closed-ended) and qualitative (open-ended) data, integrates the two, and then draws interpretations based on the combined strengths of both sets of data to gain insight into research problem.

\subsection{Theoretical Background and Context}

Physical activity is any bodily movement produced by skeletal muscles that requires energy expenditure (WHO, 2017). Although physical activity definitions in literature are generally directed to any bodily movement that individuals perform consciously, physical activity might also occur when individuals are unconscious (i.e. sleep movements). 
For children and youth, physical activity is a vehicle to wide range of social-based activities by providing opportunities for self-expression, building self-confidence, social interaction and integration including play, games, sports, transportation, chores, recreation, physical education or planned exercise, in the context of family, school, and community activities (WHO, 2015).

The success or failure of physical activity programs among children and youth can be based on various structural factors related to type, duration, intensity, frequency and volume of physical activity as well as the quality of the physical activity leader, regardless of whether the activity is performed individually or in groups (Weinberg \& Daniel, 2015). Children and youth should accumulate at least 60 minutes of moderate-intensity and vigorous-intensity physical activity per day for fundamental health benefits (e.g. healthy body tissues, healthy cardiovascular system, healthy psychological state) (CSEP, 2012). This recommendation is relevant to all healthy children and youth aged 5-17 years unless specific medical conditions indicate to the contrary. Whenever possible, children and youth with special needs should meet the goal of 60 minutes per day by performing activities in multiple shorter bouts spread throughout the day (e.g. 2 bouts of 30 minutes), then adding together the time spent during each of these bouts by working with health care provider to understand the types and amounts of physical activity appropriate for them considering their needs (WHO, 2010).

The type of physical activity participation of disabled children may lead to different levels of smartphone addiction among parents, however.

In today's world, technology - often associates with the internet, computers, smartphones, tablets, social networking sites, etc. - has encompassed our lives mercurially. Additionally, Samaha \& Hawi (2016) indicate that smartphones replaced personal computers and a multitude of other devices with distinct features (e.g. portability, simplicity, easy accessibility), has became indispensable part of our lives involving communication, watch and share photos and videos, play video games and music, surf the internet, use voice search, a wide variety of applications, etc. However, considering its mobile and internet combination, excessive use of smartphone may lead severe social problems to the social world people as it indicates the characteristics of addiction such as tolerance, withdrawal, difficulty of performing daily activities, or impulse control disorders as confirmed in previous research (Kwon, Kim, Cho, \& Yang, 2013).

Overall, previous research into smarthphone addiction has focused on quantitative evaluation of smartphone use among college students (Aljomaa, Al. Qudah, Albursan, Bakhiet, \& Abduljabbar, 2016; Cho \& Lee, 2015; Ozkan \& Solmaz, 2015), relationships among smartphone prevalence, depression and anxiety (Elhai, Dvorak, Levine, \& Hall, 2017; Elhai, Levine, Dvorak, \& Hall, 2016; Kumcagiz \& Gunduz, 2016) or parenting style in smartphone addiction (Bae, 2015; Lian, You, Huang, \& Yang, 2016;). In recent years, researchers have delved into various experience states of smartphone addiction through mixed methods approach (Davey \& Davey, 2014; Pearson \& Hussain, 2015; Yildirim \& Correia, 2015), as it reveals opportunity to explain what happens inside investigated social phenomenon. To date, however, not any existing research has addressed how parents' smartphone addiction levels are affected by their disabled children in the context of physical activity engagement. This is the unique contribution of the present research.

Individual people (parents) exhibit behaviors, and those behaviors are meaningful properties of the social reality. Parents' perceptions towards their own behaviors are also meaningful components of the social world. In order to address the intellectual and theoretical contributions of this work, we formulated a variation of causal and comparative research puzzles about what influence parents' smartphone addiction levels in the context of physical activity engagement of their disabled children, and how we can explain these different levels of smartphone addiction among parents (Mason, 2002). In this research, we presented a comprehensive and synergistic approach driven by this overarching hybrid research question: How do disabled children' engagement with physical activity affect their parents' smartphone addiction levels? The first two words in this research question point out that clearly interconnected quantitative and qualitative components are necessary, with do demonstrating the need for a quantitative modalities and how demonstrating the need for a qualitative follow-up. In this explanatory mixed methods research, thus, a causal-comparative investigation was followed by in-depth, phenomenological interview approach. As such, we intended to combine the QUAN $\leftarrow$ qual research strands as separate and sequential to grasp comprehensive and meaningful answers addressing the nature of mixed research question.

The purpose of this sequential explanatory mixed methods research therefore, was to quantify, conceptualize and finally try to explain the impact of disabled children' engagement with physical activity on their parents' smarthphone addiction levels.

\section{Method}

\subsection{Research Design}

The sequence of research steps in the research reflects the explanatory and predominantly quantitative focus of the study. Briefly, the research steps are as follows: First, the quantitative sample states were selected conveniently. Next, quantitative data were collected from these states and analyzed with quantitative techniques and procedures. Based on 
this initial data analysis, qualitative data were generated from a major special education centre to be analyzed. Then, quantitative and qualitative data were integrated. Finally, the quantitative and qualitative data served as hybrid source of statistical trends and individual stories and experiences.

The research discloses the value of a sequential explanatory mixed methods approach because it can produce more rigorous measures of association while explicitly valuing the volume and richness of verbal text evidence such as experience, perspectives and histories of research participant (Creswell \& Clarc, 2011; Teddlie \& Tashakkori, 2009). The quantitative, phase one, adopted the principles of causal-comparative investigation for the purpose of suiting the data to a robust research design based on positivist approaches. On the other side, shifts and trends within research traditions apart from positivist approaches have sparked off a relative acceptance of qualitative inquiry as necessary. The pragmatic trend, however, has rejected the distinction between the quantitative and the qualitative approaches and developed concurrent recognition and cooperation between them (Arnon \& Reichel, 2009). Therefore, In the qualitative, phase two, a causal-comparative investigation was followed by phenomenological interview transcripts through the interpretivist approach intended to accommodate far ranging and alternate insider views, rather than outcomes that reflect mainstream opinion with no consideration of variation. To address the intellectual and theoretical contributions of the qualitative phase for the quantitative phase, we used abductive research strategy. Blaikie (2009) mentioned the following about this strategy:

The starting-point is the social world of social actors being investigated their construction of reality, their way of conceptualizing and giving meaning to their social world, their tacit knowledge. This can only be discovered from the accounts which social actors provide. Their realty, the way they have constructed and interpreted their activities together, is embedded in their language.

Implementation of the mixed methods research through data sources, methods and approaches were presented hereafter.

\subsection{Quantitative Phase}

To set project in motion, bilateral negotiations and links were made between research team and a major special education centre located in one city in the southwestern Turkey, and accordingly full authorization and cooperation from this centre were obtained. In the ethical framework of the research, ethics committee approval was also received from a state university. Upon completion of the initial protocols, the research team has visited the special education centre on several occasions attentive to reach the quantitative data sources. Signing off on an informed consent form to officially agree to take part in this explanatory mixed methods study, one hundred sixteen parents who have disabled children were recruited through the techniques and procedures of the convenience sampling late in 2016.

In accordance with subject matter experts, a general poll survey was developed by authors to get answers to closed questions addressing parent's background demographic details and physical activity engagement of their disabled children. Parents were informed that the closed questions on the general poll survey pertain to children' participation in physical activity involve merely the sports, recreation, game, physical education or planned exercise aspects of the physical activity, rather than transportation or chores. Upon completion of the general pool survey, the data attentive to measure the levels of smartphone addiction of parents was collected through Turkish Version of Smartphone Addiction Scale (TSAS) adapted by Demirci, Orhan, Demirdas, Akpinar, \& Sert (2014). TSAS is a 6-point likert-type scale including thirty-three items and seven subscales. TSAS Cronbach's alpha internal consistency coefficient was calculated to be $\alpha=.95$. For TSAS seven subscales, the Cronbach's alpha internal consistency coefficients were respectively calculated to be: $\alpha=.92$ "disturbing daily life and tolerance", $\alpha=.89$ "withdrawal symptoms", $\alpha=.83$ "positive anticipation", $\alpha=.82$ "cyberspace-oriented relationships", $\alpha=.69$ "overuse", $\alpha=.82$ "social network dependence", $\alpha=.57$ "physical symptoms". In our study, TSAS Cronbach's alpha internal consistency coefficient was calculated to be $\alpha=.97$. For TSAS seven subscales, the Cronbach's alpha internal consistency coefficients were respectively calculated to be: $\alpha=.91$ "disturbing daily life and tolerance", $\alpha=.91$ "withdrawal symptoms", $\alpha=.79$ "positive anticipation", $\alpha=.91$ "cyberspace-oriented relationships", $\alpha=.84$ "overuse", $\alpha=.88$ "social network dependence", $\alpha=.60$ "physical symptoms".

\subsection{Qualitative Phase}

Few mounts later to go beyond the data, voluntary parents who have been counted in the quantitative phase of the research were secured homogeneously intended to satisfy the need for a qualitative follow-up. Participants agreed to take part in this study based on anonymity, and all names of individuals and places were pseudonyms. In the participant selection process, we determined two criteria for enough. These were saturation and sufficiency (Seidman, 2006). When saturation began to emerge from the data, no further efforts were made to secure participants. Thus, the final study group consisted of two male and three female total five respondents with an average of 50.4 years ( $\mathrm{SD}=8.8$ ). In search for sufficiency, however, the participants were selected merely from the parents who took part in the quantitative phase of the research. The qualitative empirical component of this article derives from phenomenological, in-depth interviews we conducted during the course of a follow-up investigation in 2017. The interviews were concerned with the insider views of research participants towards the findings of quantitative phase of this research. In an effort to generate valid 
data emerged from participants' causal reasoning, we broached interview guide to the subject matter experts, and it found to be highly effective with little correction. In the sequel, we hold two pilot interviews to elucidate the intelligibility of the interview guide. Next, we carried out contextual, situational and interactional interviews with the pre-existing participants to draw upon or conjure up, as fully as possible, the interpretations and views towards the findings of phase one which this research interested in explaining (Hollway \& Jefferson, 2013). The interviews ranged in length from 8 to 12 minutes, and each was letter transcribed for use in analysis of participants' responses.

\subsection{Mixed Data Analysis}

In keeping with mixed methods approach, quantitative and qualitative analysis were conducted in separately, tandem and predominantly quantitative focus of the study. In phase one, the quantitative data were analyzed using the techniques of causal-comparative approach and software package SPSS 21. In testing whether the distribution is normal, we performed the normality tests, e.g. Kolmogorov-Simirnov, and checked the output of explore section to quantify and determine the normality for a better understanding. For each group, assumptions towards data were normal. However, student's t-test for independent two groups was performed on SPSS to go beyond the data. In phase two, the qualitative follow up data were analyzed through phenomenological content analysis and software package NVivo 11 Plus to search for specific statements, themes and all possible meanings towards the phase one.

\section{Results}

\subsection{Quantitative Results}

The quantitative phase of this research seeks to find answers to that component question: Are parents' smartphone addiction levels different on variables of (a) gender, (b) parents watching their children while engaging in physical activity, (c) duration of children' daily engagement with physical activity, and (d) parents-children engagement with physical activity together? Although investigating age and gender as independent variable was beyond the scope of broader research topic, these two variables were considered to be central components as they can contribute to collective understanding into social phenomenon under investigation. Age was excluded since all parents were assigned in the adult age group, however. In addition to age, variable of parents-children engagement with physical activity together was also excepted since no significant difference was emerged. Consequently, ultimate independent variables were presented in Table 1.

Table 1. Sequence of independent variables

\begin{tabular}{|c|c|c|c|}
\hline Variable & Group & Frequency & Percentage \\
\hline \multirow{2}{*}{ Parents'gender } & Male & 55 & 47.4 \\
\hline & Female & 61 & 52.6 \\
\hline \multirow{5}{*}{$\begin{array}{l}\text { Parents watching their children while engaging in physical } \\
\text { activity } \\
\text { Duration of children' daily engagement with physical } \\
\text { activity }\end{array}$} & Yes & 104 & 89.7 \\
\hline & No & 12 & 10.3 \\
\hline & $60 \mathrm{~min}$ & 28 & 24.1 \\
\hline & More than $60 \mathrm{~min}$. & 88 & 75.9 \\
\hline & Total & 116 & 100 \\
\hline
\end{tabular}

Quantitative evidence that justifies different levels of parents' smartphone addiction on the basis of gender was illustrated in Table 2.

Table 2. The t-test analysis results for smartphone addiction levels of parents with gender variable

\begin{tabular}{|c|c|c|c|c|c|c|}
\hline Survey & Group & $\mathrm{N}$ & $\mathrm{M}$ & $\mathrm{sd}$ & $\mathrm{t}$ & df \\
\hline \multirow{2}{*}{ Total } & Male & 55 & 123.53 & 23.92 & \multirow{2}{*}{2.32} & \multirow{2}{*}{114} \\
\hline & Female & 61 & 110.98 & 33.82 & & \\
\hline \multirow{2}{*}{ Disturbing Daily Life and Tolerance } & Male & 55 & 31.33 & 6.33 & \multirow{2}{*}{2.50} & \multirow{2}{*}{114} \\
\hline & Female & 61 & 27.70 & 9.17 & & \\
\hline \multirow{2}{*}{ Withdrawal Symptoms } & Male & 55 & 24.75 & 6.47 & \multirow{2}{*}{1.56} & \multirow{2}{*}{114} \\
\hline & Female & 61 & 22.59 & 8.19 & & \\
\hline \multirow{2}{*}{ Positive Anticipation } & Male & 55 & 17.69 & 3.82 & \multirow{2}{*}{.38} & \multirow{2}{*}{114} \\
\hline & Female & 61 & 17.38 & 4.95 & & \\
\hline \multirow{2}{*}{ Cyberspace-Oriented Relationships } & Male & 55 & 14.85 & 4.24 & \multirow{2}{*}{2.78} & \multirow{2}{*}{114} \\
\hline & Female & 61 & 12.41 & 5.24 & & \\
\hline \multirow{2}{*}{ Overuse } & Male & 55 & 15.73 & 3.82 & \multirow{2}{*}{2.07} & \multirow{2}{*}{114} \\
\hline & Female & 61 & 14.07 & 4.81 & & \\
\hline \multirow{2}{*}{ Social Network Dependence } & Male & 55 & 7.82 & 2.15 & \multirow{2}{*}{1.92} & \multirow{2}{*}{114} \\
\hline & Female & 61 & 6,90 & 2,96 & & \\
\hline \multirow{2}{*}{ Physical Symptoms } & Male & 55 & 11.36 & 2.14 & \multirow{2}{*}{2.88} & \multirow{2}{*}{114} \\
\hline & Female & 61 & 9.93 & 3.15 & & \\
\hline
\end{tabular}


On average of TSAS total score, smartphone addiction levels of male parents $(\mathrm{M}=123.53, \mathrm{SE}=3.23)$ were greater than female $(\mathrm{M}=110.98, \mathrm{SE}=4.33)$. The difference was significant $\mathrm{t}(114)=2.32, \mathrm{p}<.05$; however it did represent a medium-sized effect $\mathrm{r}=.43$.

On average of disturbing daily life and tolerance subscale score, smartphone addiction levels of male parents $(\mathrm{M}=31.33$, $\mathrm{SE}=.85)$ were greater than female $(\mathrm{M}=27.70, \mathrm{SE}=1.17)$. The difference was significant $\mathrm{t}(114)=2.50, \mathrm{p}<.05$; however it did represent a medium-sized effect $\mathrm{r}=.46$. On average of withdrawal symptoms subscale score, smartphone addiction levels of male parents $(\mathrm{M}=24.75, \mathrm{SE}=.87)$ were greater than female $(\mathrm{M}=22.59, \mathrm{SE}=1.05)$. The difference was not significant $\mathrm{t}(114)=1.56, \mathrm{p}>.05$. On average of positive anticipation subscale score, smartphone addiction levels of male parents $(\mathrm{M}=17.69, \mathrm{SE}=.51)$ were greater than female $(\mathrm{M}=17.38, \mathrm{SE}=.63)$. The difference was not significant $\mathrm{t}(114)=.38$, p>.05. On average of cyberspace oriented relationships subscale, smartphone addiction levels of male parents ( $\mathrm{M}=14.85$, $\mathrm{SE}=.57)$ were greater than female $(\mathrm{M}=12.41, \mathrm{SE}=.67)$. The difference was significant $\mathrm{t}(114)=2.78, \mathrm{p}<.05$; however it did represent a large-sized effect $\mathrm{r}=.52$. On average of overuse subscale score, smartphone addiction levels of male parents $(\mathrm{M}=15.73, \mathrm{SE}=.51)$ were greater than female $(\mathrm{M}=14.07, \mathrm{SE}=.62)$. The difference was significant $\mathrm{t}(114)=2.07$, $\mathrm{p}<.05$; however it did represent a medium-sized effect $\mathrm{r}=.38$. On average of social network dependence subscale score, smartphone addiction levels of male parents $(\mathrm{M}=7.82, \mathrm{SE}=.29)$ were greater than female $(\mathrm{M}=6.90, \mathrm{SE}=.38)$. The difference was not significant $\mathrm{t}(114)=1.92, \mathrm{p}>.05$. On average of physical symptoms subscale score, smartphone addiction levels of male parents $(\mathrm{M}=11.36, \mathrm{SE}=.29)$ were greater than female $(\mathrm{M}=9.93, \mathrm{SE}=.40)$. The difference was significant $\mathrm{t}(114)=2.88, \mathrm{p}<.05$; however it did represent a large-sized effect $\mathrm{r}=.54$.

Quantitative evidence that justifies different levels of parents' smartphone addiction on the basis of parents watching their children while engaging in physical activity was illustrated in Table 3.

On average of TSAS total score, smartphone addiction levels of parents who watch their children while engaging in physical activity $(\mathrm{M}=118.79, \mathrm{SE}=2.94)$ were greater than those who don't $(\mathrm{M}=100.83, \mathrm{SE}=7.64)$. The difference was significant $\mathrm{t}(114)=1.98, \mathrm{p}<.05$; however it did represent a large-sized effect $\mathrm{r}=.60$. On average of disturbing daily life and tolerance subscale score, smartphone addiction levels of parents who watch their children while engaging in physical activity $(\mathrm{M}=29.78, \mathrm{SE}=.80)$ were greater than those who don't $(\mathrm{M}=26.33, \mathrm{SE}=2.22)$. The difference was not significant $\mathrm{t}(114)=1.40, \mathrm{p}>.05$.

Table 3. The t-test analysis results for smartphone addiction levels of parents with parents watching their children while engaging in physical activity

\begin{tabular}{|c|c|c|c|c|c|c|}
\hline Survey & Groups & $\mathrm{N}$ & $\mathrm{M}$ & sd & $\mathrm{t}$ & df \\
\hline \multirow{2}{*}{ Total } & Yes & 104 & 118.79 & 30.03 & \multirow[b]{2}{*}{1.98} & \multirow{2}{*}{114} \\
\hline & No & 12 & 100.83 & 26.48 & & \\
\hline \multirow{2}{*}{ Disturbing Daily Life and Tolerance } & Yes & 104 & 29.78 & 8.13 & \multirow{2}{*}{1.40} & \multirow{2}{*}{114} \\
\hline & No & 12 & 26.33 & 7.68 & & \\
\hline \multirow{2}{*}{ Withdrawal Symptoms } & Yes & 104 & 24.19 & 7.33 & \multirow{2}{*}{2.52} & \multirow{2}{*}{114} \\
\hline & No & 12 & 18.58 & 6.97 & & \\
\hline \multirow{2}{*}{ Positive Anticipation } & Yes & 104 & 17.84 & 4.38 & \multirow{2}{*}{2.26} & \multirow{2}{*}{114} \\
\hline & No & 12 & 14.84 & 4.11 & & \\
\hline \multirow{2}{*}{ Cyberspace-Oriented Relationships } & Yes & 104 & 13.86 & 4.94 & \multirow{2}{*}{1.87} & \multirow{2}{*}{114} \\
\hline & No & 12 & 11.08 & 4.21 & & \\
\hline \multirow{2}{*}{ Overuse } & Yes & 104 & 15.07 & 4.46 & \multirow{2}{*}{1.54} & \multirow{2}{*}{114} \\
\hline & No & 12 & 13.00 & 3.86 & & \\
\hline \multirow{2}{*}{ Social Network Dependence } & Yes & 104 & 7.42 & 2.68 & \multirow{2}{*}{1.05} & \multirow{2}{*}{114} \\
\hline & No & 12 & 6.58 & 2.23 & & \\
\hline \multirow{2}{*}{ Physical Symptoms } & Yes & 104 & 10.63 & 2.88 & \multirow{2}{*}{.25} & \multirow{2}{*}{114} \\
\hline & No & 12 & 10.42 & 2.11 & & \\
\hline
\end{tabular}

On average of withdrawal symptoms subscale score, smartphone addiction levels of parents who watch their children while engaging in physical activity $(\mathrm{M}=24.19, \mathrm{SE}=.72)$ were greater than those who don't $(\mathrm{M}=18.58, \mathrm{SE}=2.01)$. The difference was significant $\mathrm{t}(114)=2.52, \mathrm{p}<.05$; however it did represent a large-sized effect $\mathrm{r}=.77$. On average of positive anticipation subscale score, smartphone addiction levels of parents who watch their children while engaging in physical activity $(M=17.84, S E=.43)$ were greater than those who don't $(M=14.83, S E=1.19)$. The difference was significant $\mathrm{t}(114)=2.26, \mathrm{p}<.05$; however it did represent a large-sized effect $\mathrm{r}=.69$. On average of cyberspace oriented relationships subscale score, smartphone addiction levels of parents who watch their children while engaging in activity $(\mathrm{M}=13.86$, $\mathrm{SE}=.48)$ were greater than those who don't $(\mathrm{M}=11.08, \mathrm{SE}=1.22)$. The difference was not significant $\mathrm{t}(114)=1.87, \mathrm{p}>.05$. On average of overuse subscale score, smartphone addiction levels of parents who watch their children while engaging in physical activity $(\mathrm{M}=15.07, \mathrm{SE}=.44)$ were greater than those who don't $(\mathrm{M}=13.00, \mathrm{SE}=1.11)$. The difference was not significant $\mathrm{t}(114)=1.54, \mathrm{p}>.05$. On average of social network dependence subscale score, smartphone addiction levels of 
parents who watch their children while engaging in physical activity $(\mathrm{M}=7.42, \mathrm{SE}=.26)$ were greater than those who don't $(\mathrm{M}=6.58, \mathrm{SE}=.65)$. The difference was not significant $\mathrm{t}(114)=1.05, \mathrm{p}>.05$. On average of physical symptoms subscale score, smartphone addiction levels of parents who watch their children while engaging in physical activity $(\mathrm{M}=10.63, \mathrm{SE}=.28)$ were greater than those who don't $(\mathrm{M}=10.42, \mathrm{SE}=.61)$. The difference was not significant $\mathrm{t}(114)=.25, \mathrm{p}>.05$.

Quantitative evidence that justifies different levels of parents' smartphone addiction on the basis of duration of children' daily engagement with physical activity was illustrated in Table 4.

On average of TSAS total score, smartphone addiction levels of parents whose children engaging in physical activity more than 60 min. $(M=100.57, S E=5.17)$ were greater than whose children participation in 60 min. $(M=122.14$, $\mathrm{SE}=3.11)$. The difference was significant $\mathrm{t}(114)=-3.46, \mathrm{p}<.05$; however it did represent a large-sized effect $\mathrm{r}=-.75$.

On average of disturbing daily life and tolerance subscale score, smartphone addiction levels of parents whose children engaging in physical activity more than $60 \mathrm{~min}$. $(\mathrm{M}=26.71, \mathrm{SE}=1.35)$ were greater than whose children participation in 60 min. $(\mathrm{M}=30.28, \mathrm{SE}=.88)$. The difference was significant $\mathrm{t}(114)=-2.05, \mathrm{p}<.05$; however it did represent a large-sized effect $r=-.45$. On average of withdrawal symptoms subscale score, smartphone addiction levels of parents whose children engaging in physical activity more than $60 \mathrm{~min} .(\mathrm{M}=18.89, \mathrm{SE}=1.41)$ were greater than whose children participation in 60 min. $(\mathrm{M}=25.11, \mathrm{SE}=.73)$. The difference was significant $\mathrm{t}(114)=-4.10, \mathrm{p}<.05$; however it did represent a large-sized effect $\mathrm{r}=-.89$.

Table 4. The t-test analysis results for smartphone addiction levels of parents with duration of children' daily engagement with physical activity

\begin{tabular}{|c|c|c|c|c|c|c|}
\hline Survey & Groups & $\mathrm{N}$ & $\mathrm{M}$ & sd & $\mathrm{t}$ & df \\
\hline \multirow{2}{*}{ Total } & $60 \mathrm{~min}$. & 28 & 100.57 & 27.36 & \multirow{2}{*}{-3.46} & \multirow{2}{*}{114} \\
\hline & More than $60 \mathrm{~min}$. & 88 & 122.14 & 29.16 & & \\
\hline \multirow{2}{*}{ Disturbing Daily Life and Tolerance } & $60 \mathrm{~min}$. & 28 & 26.71 & 7.12 & \multirow{2}{*}{-2.05} & \multirow{2}{*}{114} \\
\hline & More than $60 \mathrm{~min}$. & 88 & 30.28 & 8.26 & & \\
\hline \multirow{2}{*}{ Withdrawal Symptoms } & $60 \mathrm{~min}$. & 28 & 18.89 & 7.44 & \multirow{2}{*}{-4.09} & \multirow{2}{*}{114} \\
\hline & More than $60 \mathrm{~min}$. & 88 & 25.11 & 6.86 & & \\
\hline \multirow{2}{*}{ Positive Anticipation } & $60 \mathrm{~min}$. & 28 & 15.00 & 3.69 & \multirow{2}{*}{-3.64} & \multirow{2}{*}{114} \\
\hline & More than $60 \mathrm{~min}$. & 88 & 18.33 & 4.37 & & \\
\hline \multirow{2}{*}{ Cyberspace-Oriented Relationships } & $60 \mathrm{~min}$. & 28 & 10.79 & 5.04 & \multirow{2}{*}{-3.61} & \multirow{2}{*}{114} \\
\hline & More than $60 \mathrm{~min}$. & 88 & 14.45 & 4.57 & & \\
\hline \multirow{2}{*}{ Overuse } & $60 \mathrm{~min}$. & 28 & 13.11 & 3.91 & \multirow{2}{*}{-2.45} & \multirow{2}{*}{114} \\
\hline & More than $60 \mathrm{~min}$. & 88 & 15.41 & 4.46 & & \\
\hline \multirow{2}{*}{ Social Network Dependence } & $60 \mathrm{~min}$. & 28 & 6.71 & 2.81 & \multirow{2}{*}{-1.44} & \multirow{2}{*}{114} \\
\hline & More than $60 \mathrm{~min}$. & 88 & 7.53 & 2.56 & & \\
\hline \multirow{2}{*}{ Physical Symptoms } & $60 \mathrm{~min}$. & 28 & 9.36 & 2.00 & \multirow{2}{*}{-2.80} & \multirow{2}{*}{114} \\
\hline & More than $60 \mathrm{~min}$. & 88 & 11.01 & 2.91 & & \\
\hline
\end{tabular}

On average of positive anticipation subscale score, smartphone addiction levels of parents whose children participation in physical activity more than $60 \mathrm{~min}$. $(\mathrm{M}=15.00 \mathrm{SE}=.70)$ were greater than whose children participation in $60 \mathrm{~min}$. $(\mathrm{M}=18.33, \mathrm{SE}=.47)$. The difference was significant $\mathrm{t}(114)=-3.64, \mathrm{p}<.05$; however it did represent a large-sized effect $\mathrm{r}=-.79$. On average of cyberspace oriented relationships subscale score, smartphone addiction levels of parents whose children participation in physical activity more than $60 \mathrm{~min}$. $(\mathrm{M}=10.79, \mathrm{SE}=.95)$ were greater than whose children participation in 60 min. ( $\mathrm{M}=14.45, \mathrm{SE}=.49)$. The difference was significant $\mathrm{t}(114)=-03.61, \mathrm{p}<.05$; however it did represent a large-sized effect $\mathrm{r}=-.78$. On average of overuse subscale score, smartphone addiction levels of parents whose children participation in physical activity more than $60 \mathrm{~min}$. $(\mathrm{M}=13.11, \mathrm{SE}=.74)$ were greater than whose children participation in $60 \mathrm{~min}$. (M=15.41, SE=.48). The difference was significant $\mathrm{t}(114)=2.45, \mathrm{p}<.05$; however it did represent a large-sized effect $r=-.53$. On average of social network dependence subscale score, smartphone addiction levels of Parents whose children participation in physical activity more than $60 \mathrm{~min}$. $(\mathrm{M}=6.72, \mathrm{SE}=.53)$ were greater than whose children participation in $60 \mathrm{~min}$. $(\mathrm{M}=7.53, \mathrm{SE}=.27)$. The difference was not significant $\mathrm{t}(114)=1.44, \mathrm{p}>.05$. On average of physical symptoms subscale score, smartphone addiction levels of Parents whose children participation in physical activity more than $60 \mathrm{~min}$. $(\mathrm{M}=9.36, \mathrm{SE}=.38)$ were greater than whose children participation in $60 \mathrm{~min}$. $(\mathrm{M}=11.01, \mathrm{SE}=.31)$. The difference was significant $\mathrm{t}(114)=2.80, \mathrm{p}<.05$; however it did represent a large-sized effect $\mathrm{r}=-.61$.

\subsection{Qualitative Results}

For cantilevered theoretical explanations pertinent to quantitative findings of the explanatory mixed methods study, a follow-up qualitative inquiry was conducted through this stage. In the semantic networks, we created categories which 
were linked with quantitative findings so that aspects of the investigated social phenomenon could be explained thoroughly. The analysis of the interview transcripts emerged three follow up themes: (a) Male dominance in smartphone use, (b) parents passive participation in physical activity with or without smartphones and (c) levels of smartphone addiction among parents in terms of duration of their children daily physical activity.

\subsubsection{Theme One: Male Dominance in Smartphone Use}

We conducted interviews with parents to understand the construction of reality embedded in their tacit knowledge and language towards gender variable which was statistically analyzed in the phase one. Two voices say:

Cumali (Male): In parents with disabled children, mothers have to take care of their children as housewives. In the meantime, they do not have enough time to be overly dependent on their smartphones. Men, on the other hand, always work in the field and get more free time from their females, whether in the workplace or in a friend's environment.

Fadime (Female): Well... Mothers always keep an eye on their children with disabilities because they have motherhood instincts. Fathers also keep an eye on them, but they stay outside to work longer than we do. Accordingly, they are more dependent on their phones than we are.

\subsubsection{Theme Two: Parents Passive Participation in Physical Activity with or without Smartphones}

The phenomenological follow up interview transcripts enabled us to answer outputs of the parents' smartphone addiction levels affected by watching their children while participate in physical activity. Two interviewed persons have given the following interpretations to such discussions:

Bayram (Male): When special parents take their children to the park to play games, they immediately heat for their smartphones, and they spend their time with it while their children play. I think that's the reason why parents who say that they watch their children while participating in physical activity are more addicted than those who do not watch.

Selma (Female): We say we are watching our children, but we spend time with the smartphones at the same time I think.

3.2.3 Theme Three: Levels of Smartphone Addiction among Parents in Terms of Duration of Their Children Daily Physical Activity Engagement

To consolidate the quantitative first phase of this research we conducted interviews and asked question pertain to the statistical results of the parents smatphone addiction levels according to duration of their children daily participation in physical activity. From a viewer's perspective:

Sureyya (Female): When parents are separated from their children, that is, their responsibilities over children decrease, their dependence on smartphones increase more. Special children' participation in physical activity under the supervision of a health care provider, a coach or a teacher is also the main reason for different levels of smartphone addiction among parents.

\section{Drawing Conclusions, Interpretations and Data Mixing}

The purpose of this sequential explanatory mixed methods research was to quantify, conceptualize and finally try to explain the impact of disabled children' engagement with physical activity on their parents' smartphone addiction levels with genially integration of data from both closed-ended and open-ended questions.

Quantitative phase of this research indicated that smartphone addiction levels of male parents are greater than female on the whole questionnaire and all of its dimensions with the exception of the positive anticipation dimension. This result is consistent with the findings conducted by S.S. Aljomaa, Al.qudah, Albursan, Bakhiet, \& Abduljabbar (2016), which indicated that significant gender differences in a group of King Saud University students were found in the degree of addiction on the whole questionnaire and all of its dimensions with the exception of the technological dimension in favor of males. However, this finding was not consistent with study of Ok \& Hwa (2016), Randler et al. (2016) and Van Deursen, Bolle, Hegner, \& Kommers (2015) where females were reported to use smartphones more often than males. The follow-up component of this study then explained how male parents exhibit more addicted behavior to smartphones than female. One interviewed person has given the following interpretations to such discussions:

Fadime (Female): Well... Mothers always keep an eye on their children with disabilities because they have motherhood instincts. Fathers also keep an eye on them, but they stay outside to work longer than we do. Accordingly, they are more dependent on their smartphones than we are.

Thus, we can conclude that parents' personal approaches to smartphone addiction vary considerably in terms of gender, with the type of approach relating to personal liability, task sharing, life style, habit, socio-cultural structure and living environment. Thus, women's health courses regarding this type of addictions should become part of the regular college or university curriculum in Turkey. Also, greater opportunities for peer group interactions should be provided.

Statistical analyzes of the closed-ended questions showed that parents watching their disabled children during physical 
activity exhibit more smartphone-addicted behaviors than non-watching parents. The opinion of two interviewees on this finding was as follows:

Bayram (Male): When special parents take their children to the park to play games, they immediately heat for their smartphones, and they spend their time with it while their children play. I think that's the reason why parents who say that they watch their children while participating in physical activity are more addicted than those who do not watch.

Selma (Female): We say we are watching our children, but we spend time with smartphones at the same time I think.

We can draw the conclusion from these interpretations that parents who say that they watch their children while they are participating in physical activity actually exhibit behaviors that are dependent on their smartphones within this time period. To decrease the number of parents who assessed themselves as smartphone addicted, we must promote of healthy life style behaviors in the area of physical activity, mental health care, environmental health, health maintenance self-care and resting.

Finally, the result of the phase one indicated that the levels of smartphone addiction of parents whose disabled children participated in more than 60 minutes of physical activity were greater than the levels of smartphone addiction of parents whose disabled children participated in 60 minutes of physical activity. In order to gain insight into the construction of reality embedded in parents' tacit knowledge and language towards this result, one interviewed parent echoed the following opinion:

Sureyya (Female): When parents are separated from their children, that is, their responsibilities over children decrease, their dependence on smartphones increase more. Special children' participation in physical activity under the supervision of a health care provider, a coach or a teacher is also the main reason for different levels of smartphone addiction among parents.

Consequently, we can propose that parents, whose children are more involved in the physical activity, find the opportunity to create more free time for the smartphones. Accordingly this may lead to addicted behaviors to smartphones among parents. At this stage, parents' active participation in physical activity with their disabled children can be recommended. Also, parents should take fields notes of their children while participation in physical activity.

\section{Research Limitations}

The scope of the existing research into the present study is scant. This brought about the outputs of the study not to be discussed in detailed with previous research. Another limitation of this study is that the qualitative phase of the research is limited by verbal capacities of the participants. This is the limitations of the qualitative follow-up data obtained though interviews. Thus, it affects the whole of the study under the mixed methods research pattern.

\section{Future Research}

Given the present and previous research, at least two avenue of future research are pertinent. Future research should explore the smartphone addiction of disabled children regarding how they place sports, game, play, planned exercises, recreation or physical education in their life. Finally, the present and previous physical activity studies have failed to address the complete benefits of smartphone addiction reduction in children with different disability groups. This leaves several important questions unanswered. For example, does physical activity participation boost the reduction of smartphone addiction among disabled children? In any event, many topics related to smartphone addiction remain unexplored.

\section{Acknowledgements}

An earlier version of this article was presented orally at the 8th International Conference on Psychology, Language and Teaching, Dubai, United Arab Emirates, on December 19-20, 2016.

\section{Declaration of Conflicting Interests}

The author(s) declared no potential conflicts of interest with respect to the research, authorship, and/or publication of this article.

\section{References}

Aljomaa, S. S., Al. Qudah, M. F., Albursan, I. S., Bakhiet, S. F., \& Abduljabbar, A. S. (2016). Smartphone addiction among university students in the light of some variables. Computers in Human Behavior, 61, 155-164. https://doi.org/10.1016/j.chb.2016.03.041

Aljomaa, S. S., Al.qudah, M. F., Albursan, I. S., Bakhiet, S. F., \& Abduljabbar, A. S. (2016). Smartphone addiction among university students in the light of some variables. Computers in Human Behavior, 61. https://doi.org/10.1016/j.chb.2016.03.041 
Arnon, S., \& Reichel, N. (2009). Closed and open-ended question tools in a telephone survey about "the good teacher": An example of a mixed method study. Journal of Mixed Methods Research, 3(2), 172-196. https://doi.org/10.1177/1558689808331036

Bae, S. M. (2015). The relationships between perceived parenting style, learning motivation, friendship satisfaction, and the addictive use of smartphones with elementary school students of South Korea: using multivariate latent growth modeling. School Psychology International, 36(5), 513-531. https://doi.org/10.1177/0143034315604017

Blaikie, N. (2009). Designing social research (2nd Editio). Malden, USA: Polity Press.

Bryman, A. (2007). Barriers to integrating quantitative and qualitative research. Journal of Mixed Methods Research, l(1), 8-22. https://doi.org/10.1177/2345678906290531

Cho, S., \& Lee, E. (2015). Development of a brief instrument to measure smartphone addiction among nursing students. CIN: Computers, Informatics, Nursing, 33(5), 2016-224. https://doi.org/10.1097/CIN.0000000000000132

Creswell, J. W. (2014). A concise introduction to mixed methods research (1th ed.). Thousand Oaks, California: Sage Publication.

Creswell, J. W., \& Clarc, V. L. P. (2011). Desing and conducting: Mixed methods research (2nd ed.). Thousand Oaks, California: Sage Publication.

CSEP. (2012). CSEP Canadian physical activity and sedentary behaviour guidelines. Canada: CSEP | SCPE.

Davey, S., \& Davey, A. (2014). Assessment of smartphone addiction in Indian adolescents: a mixed method study by systematic-review and meta-analysis approach. International Journal of Preventive Medicine, 5(12), 1500-1511.

Demirci, K., Orhan, H., Demirdas, A., Akpinar, A., \& Sert, H. (2014). Validity and reliability of the turkish version of the smartphone addiction scale in a younger population. Bulletin of Clinical Psychophamacology, 24(3), 226-234. https://doi.org/10.5455/bcp.20140710040824

Elhai, J. D., Dvorak, R. D., Levine, J. C., \& Hall, B. J. (2017). Problematic smartphone use: a conceptual overview and systematic review of relations with anxiety and depression psychopathology. Journal of Affective Disorders, 207, 251-259. https://doi.org/10.1016/j.jad.2016.08.030

Elhai, J. D., Levine, J. C., Dvorak, R. D., \& Hall, B. J. (2016). Fear of missing out, need for touch, anxiety and depression are related to problematic smartphone use. Computers in Human Behavior, 63, 509-516. https://doi.org/10.1016/j.chb.2016.05.079

Hollway, W., \& Jefferson, T. (2013). Doing qualitative research differently: A psychosocial approach. (K. Metzler, Ed.) (2nd Editio). London: SAGE.

Kumcagiz, H., \& Gunduz, Y. (2016). Relationship between psychological well-being and smartphone addiction of university students. International Journal of Higher Education, 5(4), 144-156. https://doi.org/10.5430/ijhe.v5n4p144

Kwon, M., Kim, D., Cho, H., \& Yang, S. (2013). The smartphone addiction scale: Development and validation of a short version for adolescents. Journal of PLOS One, 8(12), 1-7. https://doi.org/10.1371

Lian, L., You, X., Huang, J., \& Yang, R. (2016). Who overuses smartphones? roles of virtues and parenting style in Smartphone addiction among Chinese college students. Computers in Human Behavior, 65, 92-99. https://doi.org/10.1016/j.chb.2016.08.027

Mason, J. (2002). Qualitative researching (2th Editio). Great Britain: Cromwell Press.

Ok, I., \& Hwa, S. (2016). Effects of academic stress in middle school students on smartphone addiction: Moderating effect of self-esteem and self-control. J Korean Acad Psychiatr Ment Health Nurs ISSN, 25(3), 262-271. https://doi.org/10.12934/jkpmhn.2016.25.3.262

Ozkan, M., \& Solmaz, B. (2015). Mobile addiction of generation Z and its effects on their social lifes: (an application among university students in the 18-23 age group). Procedia - Social and Behavioral Sciences, 205, 92-98. https://doi.org/10.1016/j.sbspro.2015.09.027

Pearson, C., \& Hussain, Z. (2015). Smartphone use, addiction, narcissism, and personality: a mixed methods investigation. International Journal of Cyber Behavior, Psychology and Learning, 5(1), 17-32. https://doi.org/10.4018/ijcbpl.2015010102

Randler, C., Wolfgang, L., Matt, K., Demirhan, E., Horzum, M. B., \& Beşoluk, S. (2016). Smartphone addiction proneness in relation to sleep and morningness-eveningness in german adolescents. Journal of Behavioral Addictions, 5(3). https://doi.org/10.1556/2006.5.2016.056 
Samaha, M., \& Hawi, N. S. (2016). Relationships among smartphone addiction, stress, academic performance, and satisfaction with life. Computers in Human Behavior, 57, 321-325. https://doi.org/10.1016/j.chb.2015.12.045

Seidman, I. (2006). Interviewing as qualitative research: A guide for researchers in education and the social sciences (3th Editio). New York: Teacher College Press.

Teddlie, C., \& Tashakkori, A. (2009). Foundations of mixed methodts research. (V. Knight, S. Connelly, L. Habib, S. K. Quesenberry, \& C. Duksta, Eds.) (First). United States of America: Sage Publication.

Van Deursen, A. J. A. M., Bolle, C. L., Hegner, S. M., \& Kommers, P. A. M. (2015). Modeling habitual and addictive smartphone behavior: The role of smartphone usage types, emotional intelligence, social stress, self-regulation, age, and gender. Computers in Human Behavior, 45. https://doi.org/10.1016/j.chb.2014.12.039

Weinberg, R. S., \& Daniel, G. (2015). Foundadion of sport and exercise psychology. (M. Schrag, A. S. Ewing, C. A. Gentis, A. Cole, \& A. M. Eastin, Eds.) (6th Editio). USA: Courier Companies.

WHO. (2010). Global Recommendations on Physical Activity for Health. World Health Organization. Switzerland: Who Press.

WHO. (2015). Physical activity and young People. Retrieved December 8, 2016, from http://www.who.int/dietphysicalactivity/factsheet_young_people/en/

WHO. (2017). Global strategy on diet, physical activity and health. Retrieved June 10, 2017, from http://www.who.int/dietphysicalactivity/pa/en/

Yildirim, C., \& Correia, A. P. (2015). Exploring the dimensions of nomophobia: development and validation of a self-reported questionnaire. Computers in Human Behavior, 49, 130-137. https://doi.org/10.1016/j.chb.2015.02.059

\section{Copyrights}

Copyright for this article is retained by the author(s), with first publication rights granted to the journal.

This is an open-access article distributed under the terms and conditions of the Creative Commons Attribution license which permits unrestricted use, distribution, and reproduction in any medium, provided the original work is properly cited. 